Louisiana State University

LSU Digital Commons

$1-1-2003$

\title{
Children's sociable and aggressive behaviour with peers: A comparison of the US and Australia, and contributions of temperament and parenting styles
}

\author{
Alan Russell \\ Flinders University \\ Craig H. Hart \\ Brigham Young University \\ Clyde C. Robinson \\ Brigham Young University \\ Susanne F. Olsen \\ Brigham Young University
}

Follow this and additional works at: https://digitalcommons.Isu.edu/biosci_pubs

\section{Recommended Citation}

Russell, A., Hart, C., Robinson, C., \& Olsen, S. (2003). Children's sociable and aggressive behaviour with peers: A comparison of the US and Australia, and contributions of temperament and parenting styles. International Journal of Behavioral Development, 27 (1), 74-86. https://doi.org/10.1080/

01650250244000038

This Article is brought to you for free and open access by the Department of Biological Sciences at LSU Digital Commons. It has been accepted for inclusion in Faculty Publications by an authorized administrator of LSU Digital Commons. For more information, please contact ir@lsu.edu. 


\title{
Children's sociable and aggressive behaviour with peers: A comparison of the US and Australia, and contributions of temperament and parenting styles
}

\author{
Alan Russell \\ Craig H. Hart \\ Brigham Young University, craig_hart@byu.edu \\ See next page for additional authors
}

Follow this and additional works at: https://scholarsarchive.byu.edu/facpub

Part of the Family, Life Course, and Society Commons

\section{Original Publication Citation}

Russell, A., Hart, C.H., Robinson, C.C., \& Olsen, S.F. (2003). Children’s sociable and aggressive behavior with peers: A comparison of the U.S and Australia, and contributions of temperament and parenting styles. International Journal of Behavioral Development, 27, 74-86. Equal Authored

\section{BYU ScholarsArchive Citation}

Russell, Alan; Hart, Craig H.; Robinson, Clyde C.; and Olsen, Susanne F., "Children's sociable and aggressive behaviour with peers: A comparison of the US and Australia, and contributions of temperament and parenting styles" (2003). All Faculty Publications. 2925.

https://scholarsarchive.byu.edu/facpub/2925 
Authors

Alan Russell, Craig H. Hart, Clyde C. Robinson, and Susanne F. Olsen 


\title{
Children's sociable and aggressive behaviour with peers: A comparison of the US and Australia, and contributions of temperament and parenting styles*
}

\author{
Alan Russell \\ The Flinders University of South Australia, Adelaide, \\ Australia
}

\author{
Craig H. Hart, Clyde C. Robinson, and \\ Susanne F. Olsen \\ Brigham Young University, Salt Lake City, USA
}

\begin{abstract}
Links between both temperament and parenting, and children's sociable and aggressive behaviour with peers (physical and relational), were examined. The research was undertaken in two Western cultures (the United States and Australia) assumed to be similar in socialisation practices and emphases. The moderating effects of parent sex and child sex were also examined. Parents completed questionnaires on parenting styles and child temperament. Preschool teachers rated children's aggressive and sociable behaviour. US children were rated higher on both types of aggression by teachers and on sociability, activity, and emotionality by parents. Girls were rated as more relationally aggressive and more prosocial than boys, with boys higher on physical aggression. Mothers were more authoritative, with fathers more authoritarian, although the latter was mainly a result obtained from US parents. In both the United States and Australia, temperament consistently predicted child sociable and aggressive behaviours, with some evidence of fathers' authoritarian parenting also contributing. The results show the relevance for parenting and child development of gender, and the importance of culture differences even between two Western and individualist countries.
\end{abstract}

\section{Introduction}

Cross-cultural research on parenting and child development has contributed to advances in the understanding of factors shaping parenting as well as processes that influence child development (Leung, Lau, \& Lam, 1998; Wu et al., in press). This cross-cultural research has mainly focused on comparisons of "Western" and "Eastern" cultures (e.g., Abe \& Izard, 1999; Leung et al., 1998; Rudy, Grusec, \& Wolfe, 1999; Xiao, 1999), usually with assumptions that these comparisons are between "individualist" and "collectivist" cultures. Broadly, this body of evidence supports a conclusion that there are differences between these cultures in parents' beliefs, values, goals, and practices (Leung et al., 1998; Pachter \& Harwood, 1996; Xiao, 1999). In an associated way, conclusions have been drawn about differences in cultural norms and interpretations or conceptions of child behaviour. Consistent with these differences in norms and interpretations, evidence has been obtained for differences in child behaviour across individualist and collectivist cultures (Abe \& Izard, 1999; Mueller et al., 1995; Stewart \& McBride-Chang, 2000).

The results from comparisons of individualist and collectivist cultures support $\mathrm{Chen}, \mathrm{Li}, \mathrm{Li}, \mathrm{Li}$, and Liu's (2000a) assertion about the importance of investigating parenting and contributions to child development in different social and cultural contexts. In order to examine this proposition fully, there is a need to extend comparisons beyond "East versus
West", with its assumed differences on the individualistcollectivist dimension. There is a body of research that has begun to do this (e.g., Bornstein et al., 1998; Lai, Zhang, \& Wang, 2000; Pavuluri \& Luk, 1996). This trend is extended in the present research, where parenting and child characteristics and behaviour, as well as links between these, were compared in samples from the United States and Australia. The comparison here is between two countries that on the surface could be assumed to be socially and culturally similar. Both countries are Western and individualist in orientation, of recent origins, with substantial immigrant populations, and both are English speaking.

Although there appear to be cultural similarities between the United States and Australia, there is some evidence suggesting possible parenting differences between the two countries. For example, Leung et al. (1998) found that Australian parents scored lower than US parents on academic authoritarianism. Bornstein et al. (1998) studied self-evaluations and attributions in parenting across seven countries. Their results indicated a number of differences among socalled Western countries.

\section{Child characteristics and behaviour}

There is a growing body of evidence pointing to cross-cultural differences in parents' ratings of child behaviour. Some of this evidence pertains to differences on the Achenbach Child
Correspondence should be addressed to Professor Alan Russell, School of Family Sciences, Zayed University-Dubai, P.O. Box 19282, Dubai, United Arab Emirates.

The authors gratefully acknowledge the contribution of the parents and teachers who participated in the research. We also acknowledge in appreciation the assistance of V. Aloa, T. Feder, A. Glover, H. Miller, and G. Palmer in the collection of the data in Australia. Judith Saebel provided expert advice and assistance with the data analysis. 
Behavior Checklist (CBCL). Several recent studies have specifically focused on child behavioural comparisons across Eastern and Western cultures (e.g., Mueller et al., 1995; Weisz, Chaiyasit, Weiss, Eastman, \& Jackson, 1995), as well as across Western cultures that are perceived to be more similar (e.g., Achenbach, Verhulst, Baron, \& Akkerhuis, 1987; Stranger, Fombonne, \& Achenbach, 1994). Regarding the latter, prior research exploring global parent-rated indices of child problem and socially adaptive behaviours indicate that Australian children, as compared with American children, are rated higher on behavioural difficulties and lower on social competency (Achenbach, Hensley, Phares, \& Grayson, 1990; Hensley, 1988). Beyond broadband internalising and externalising behavioural comparisons, however, little is known about how parent perceptions of underlying child temperamental dispositions might vary across cultures. These could include perceptions of temperamental propensities such as shyness, emotionality, activity level, and sociability (Buss \& Plomin, 1984). Although some knowledge in this regard has been gleaned from a handful of studies that include Chinese and Western mothers' perceptions of child temperament (e.g., Chen et al., 1998; Porter, Hart, Yang, Zeng, \& Robinson, 2002), little is known about similarities and differences in parent perceptions of child temperament across Western cultural settings (cf. Sanson, Hemphill, \& Smart, 2002).

In addition to parent ratings of child behaviour, we also examined teacher ratings. In this case, the focus was on teacher perceptions of narrowband behavioural subtypes, namely two types of aggression (physical, relational) and two indices of social competence (sociable and prosocial behaviour). These behavioural subtypes have garnered recent attention from investigators conducting within- and across-cultural studies (e.g., Chen et al., 2000a; Hart, Nelson, Robinson, Olsen, \& McNeilly-Choque, 1998; Tomada \& Schneider, 1997). They were selected in order to examine both positive and negative aspects of children's social behaviour and because of the distinct contributions that these behaviours make to children's social adjustment (e.g., Crick, 1996; Crick, Casas, \& Ku, 1999a). We have reason to believe that there may be differences in teacher perceptions of how frequently these subtypes occur amongst preschoolers in Australian and US cultural contexts. There are some indications, for example, that US teachers are less accepting of problem behaviour than Australian teachers (Walker \& Lamon, 1987). This tendency could lend itself to US teacher response sets that reflect a greater bias toward rating disruptive children more harshly and sociable children more positively (cf. Mueller et al., 1995; Triandis, 1994; Weisz et al., 1995). Assessing differences in how teachers identify and rate preschoolers' behavioural subtypes is an important first step toward designing future studies that incorporate observations designed to target actual behavioural display frequencies (as contrasted with teacher perceptions) in Australia and the US.

\section{Parenting}

Parenting styles have been prominent in research on culture and parenting (Chao, 2001; Chen, Liu, \& Li, 2000b; Herz \& Gullone, 1999; Lai et al., 2000; Leung et al., 1998). In this study, we measured dimensions of two parenting styles that have widely been claimed to have significant consequences for children's development, including social development (Maccoby \& Martin, 1983). These two styles are authoritative and authoritarian parenting. The dimensions were connection, regulation, and autonomy granting from the authoritative style and physical coercion, verbal hostility, and nonreasoning/ punitive from the authoritarian style (see Hart, Newell, \& Olsen, in press; Wu et al., 2002).

\section{Parent and child sex}

An important element of the focus on children's sociable and aggressive behaviour and parenting was the examination of sex differences and whether these sex differences differed for the US and Australia. With respect to child sex, considerable emphasis has been placed on relational aggression being more evident in girls than in boys. Sex differences have also been noted in the processes associated with the development of aggression in boys and in girls (Ladd \& Ladd, 1998), as well as in the consequences of aggression for boys and girls, for example in terms of peer acceptance (Crick et al., 1999b). As a consequence, Crick et al. (1999b) wrote about "unique factors in the etiology and development of relational versus physical forms of aggression for boys versus girls" (p. 132). The results of Hart, DeWolf, and Burts (1993) support a similar point for the development of sociable behaviour in boys and in girls. Block (1983) suggested that parents encourage self-assertive behaviour in boys and relationshipenhancing behaviour in girls. There is reasonable agreement about boys and girls differing in terms of prosocial orientation, and physical and relational aggression (Crick et al. 1999b; Leaper, 1994; Rubble \& Martin, 1998). An issue for the present research was whether boys and girls might differ in the development of these behavioural tendencies and whether these differences would be comparable in the US and Australian samples.

With respect to differences between mothers and fathers, there is considerable evidence of paternal and maternal differences in parenting styles and behaviour, and that mothers and fathers may have distinct influences on child development in Australian (Russell, et al. 1998) and US (Carson \& Parke, 1996; Hart, DeWolf, Wozniak, \& Burts, 1992b; Hart et al., 1998; MacDonald \& Parke, 1984; Pettit, Brown, Mize, \& Lindsey, 1998; Power, McGrath, Hughes, \& Manire, 1994) samples. An aim of the present research was to examine these similarities and differences for US and Australian mothers and fathers.

\section{Relationships between parenting and child behaviour}

The third main element of the research concerned the examination of relationships between parenting and children's social behaviour with peers. Relationships between family experiences and children's social behaviour with peers have been a focus of considerable empirical and theoretical attention over the past decade (Mize \& Pettit, 1997; Parke et al., 2002). However, much of the research linking parenting and children's aggression has focused on overt and/or physical aggression. Consequently, as Crick et al. (1999b) note, there is "little information ... currently available regarding the family relationships of relationally aggressive children" (p. 109). They argue that the theoretical and conceptual models developed for the understanding of family contributions to overt or physical aggression in children could be a useful starting place for the examination relational aggression. Claims about the distinctness of relational aggression from other forms of aggression 
(Crick et al., 1999a,b; Crick \& Werner, 1998), may suggest there are different processes associated with the development of physical versus relational aggression, yet recent research suggests that similar parenting processes are at work (Hart, Nelson et al., 1998). The present research provides an opportunity to test this prediction further in samples from the US and Australia to determine whether similar processes were evident.

Parallel to an emphasis on parenting has been work on the contribution of temperament to children's social behaviour and personality (Caspi, 1998; Caspi, Henry, McGee, Moffitt, \& Silva, 1995; Hart, Olsen, Robinson, \& Mandleco, 1997; Sanson et al., 2002; Shiner, 1998). Links between temperament and physical aggression have been explored in previous research (Keenan, Shaw, Delliquadri, Grovannelli, \& Walsh, 1998; Sanson et al., 2002). On the other hand, little if any research appears to have examined the association between child temperament and relational aggression. It has been proposed, however, that in order for relational aggression to be effective, it must occur in the context of social influence (Crick et al., 1999b). It may well be that dispositionally social children are more likely to engage in this behaviour.

Thus, in the present research, contributions of both temperament and parenting to children's social behaviour were investigated. The research enabled these contributions to be examined for samples from the US and Australia. A principal question in both samples was whether the factors (both temperamental and parenting) linked to children's relational aggression differed from factors associated with physical aggression.

Additionally, a number of scholars (e.g., Kochanska, 1995; Rothbart \& Bates, 1998) have pointed out the need for exploring interactions between child temperament and parenting in predicting the development of children's adjustment. It is possible, for example, that parenting has different effects on children's adjustment depending on the temperament of the child (see Hart et al., in press, for a recent review). It is also possible that parenting and temperament are linked to children's sociable and aggressive behaviour in different ways for boys and for girls, as suggested by a growing literature (e.g., Sanson et al., 2002; Sanson \& Rothbart, 1995; Russell \& Russell, 1996; Zahn-Waxler, 1993). These questions about the moderating role of child temperament and child sex were investigated in the present study, with attention given to whether these moderating effects differed for the US and Australia.

\section{Summary}

The main goal of the research was to compare samples from the US and Australia on (1) parent and teacher reports of children's temperament and their social behaviour with peers, (2) parent reports of parenting styles, and (3) links among child behaviour and parenting measures, with sex and child temperament considered as moderating factors. The extent to which similarities and differences are found that are in accordance with our conceptualisations outlined here would support conclusions about possible likenesses and variations in the social and cultural contexts for parenting and child development in the US and Australia. Differences found would also suggest the need for further research on these variations across so-called individualist cultures as a basis for understanding the role of social and cultural contexts in parenting and child development.

\section{Method}

\section{Participants}

In Australia, the participants were 198 families and 306 parents with a preschool child (102 girls, 95 boys) aged from 48 to 68 months ( $M=54.40$ months; $S D=3.70$ months). For 108 families, data were obtained from both mother and father, for 85 families data were obtained from mothers only, and for 5 families data were obtained from fathers only. The parents were recruited from 10 preschools in metropolitan Adelaide, South Australia. The mean age of fathers was 35.71 years ( $S D$ $=5.91)$ and of mothers was 33.61 years $(S D=5.20)$. Ninetyfive mothers indicated that they were employed, either fulltime or part-time. One hundred and sixty-six of the families described themselves as "two-parent families". Ninety-seven per cent of the sample described themselves as Caucasian. The mean number of children in the families was $2.41(S D=0.95)$. Seventy-nine children ( 45 boys, 34 girls) were in families with children of one sex only. The mean Hollingshead score was $32.48(S D=12.79)$.

In the United States, the participants were 224 families, with a total of 341 parents with a preschool child (131 boys and 93 girls) aged from 36 to 72 months $(M=59.41$ months; $S D=$ 5.41 months). For 100 families data were provided by both mother and father, for 122 families data were obtained from mothers only, and for 19 families data were obtained from fathers only. The parents were recruited from eight preschools in a moderate-sized community in the western United States (Provo, Utah). The mean age of fathers was 32.30 years $(S D=$ $6.01)$, and of mothers was 30.32 years $(S D=5.57)$. Eighty-six per cent of the sample described themselves as Caucasian, with $11 \%$ as Latino. Sixty-seven children (39 boys, 28 girls) were in families with one sex of child only, with 157 from families with children of both sexes. The mean number of children in the families was $3.1(S D=1.3)$. Ninety-three mothers indicated that they were in full-time or part-time employment. One hundred and seventy-three of the families classified themselves as two-parent families. The mean Hollingshead score for the US families was $34.04(S D=9.78)$. A $t$-test revealed no difference between the Hollingshead score for the US and Australian families. Hollingshead scores have a range of 8-66. These scores for Australia and the US show the samples to be lower middle-class. For example, these scores are between those reported by McNeilly-Choque, Hart, Robinson, Nelson, and Olsen (1996) for Head Start sample (mean of 28.13) and a university preschool sample (mean of 42.61).

\section{Measures}

For the parenting measures, mothers and fathers were asked to evaluate each item on the questionnaires based on their perceptions of how they interact with the early childhood-age target child in their particular family. Self-report and observational measures of parenting have been found to be moderately associated in previous research (Kochanska, Kuczynski, \& Radke-Yarrow, 1989; Pettit, Clawson, Dodge, \& Bates, 1996). For the measures of children's outcomes, teachers were asked 
to rate the frequency of aggressive and sociable behaviour occurrences for each child in their classroom.

Authoritative and authoritarian parenting styles. A modified version of the Parenting Styles and Dimensions (PSD) instrument (Robinson, Mandleco, Olsen, \& Hart, 2001) was completed by mothers and fathers from both samples. This instrument was developed to overcome limitations of other widely used parenting style measures for preschool-age and school-age children. The revised PSD was similar to that described in Wu et al. (in press) and included 23 items forming two patterns of parenting: authoritative and authoritarian. The authoritative pattern consisted of three stylistic dimensions: (1) Connection-warmth/acceptance (e.g., expresses affection by hugging, kissing, etc.), 6 items; (2) Regulation-reasoning/ inducation (e.g., gives child reasons why rules should be obeyed), 4 items; and (3) Autonomy granting-democratic participation (e.g., allows child to give input into family rules), 4 items. These three stylistic dimensions were summed to form a single measure of authoritative parenting. The authoritarian pattern consisted of three stylistic dimensions: (1) verbal hostility (e.g., yells and shouts when child misbehaves), 3 items; (2) physical coercion (e.g., spanks when our child is disobedient), 3 items; and (3) nonreasoning/punitive (e.g., punishes by taking privileges away from child with little if any explanations), 3 items. These three stylistic dimensions were summed to form a single measure of authoritarian parenting. Mothers and fathers independently rated themselves on each item by assessing "how often they perceived themselves exhibiting parenting behaviours reflected in each item" using a 5-point scale anchored by 1 (never) and 5 (always). Mothers and fathers also rated their spouse on each of the items. This yielded a self-report measure and a spouse-report measure of authoritative and authoritarian parenting for mothers and for fathers. Correlations between the self-report and spouse-report (e.g., fathers' reports on their authoritative parenting and mothers' reports on fathers' authoritative parenting) were all significant and ranged from .33 to .63. This shows low to moderate agreement between the self-report and spouse-report scores.

Cronbach's alpha was calculated for the authoritative and authoritarian measures, for mothers and fathers and separately for the US and Australian sample and separately for parenting boys and parenting girls. For the self-report measures of authoritative parenting the alphas ranged from .71 to .86 (mean of .81). For the spouse report measures the alphas ranged from .75 to .91 (mean of .84). For the self-reports of authoritarian parenting the alphas ranged from .69 to .80 (mean of .74). The alphas for the spouse reports of authoritarian parenting ranged from .69 to .85 (mean of .75). These show moderate to higher reliabilities.

Children's aggressive and sociable outcomes. Preschool teachers rated each child in their classroom for the frequency of aggressive and sociable behaviours on a 3-point scale (never, sometimes, often) across items representing two aggressive domains (physical, relational) and two sociable domains (prosocial, sociability). An expanded measure was extensively pilot tested by a group of teachers, who completed pilot versions on approximately 600 children aged 4 to 5 years (see Hart et al., 2000a; McNeilly-Choque et al., 1996). The reduced teacher measure used in this study consisted of 21 items with 11 items that assessed a variety of physical and relational aggressive behaviours and 10 items that assessed a variety of prosocial and sociability behaviours. In the aggressive domains, 5 items represented physical aggressive behaviours (e.g., pushes or hits when he/she wants to get something back another child has taken from them) and 6 items represented relational aggressive behaviours (e.g., tells other children not to play with or be a peer's friend). In the sociable domain, 5 items represented sociability behaviours (e.g., has many friends) and 5 items represented prosocial behaviours (e.g., comforts a child who is crying or upset). This is consistent with current research that differentiates sociable and prosocial behaviour (Chen, $\mathrm{Li}$ et al., 2000).

Cronbach's alphas were calculated for each of the teacherrated child outcome measures, separately for the US and Australian samples and separately for boys and girls. These alphas ranged from .74 to .92 (mean of .88). These indicate moderate to high reliabilities.

\section{Child temperament}

Child temperament was measured with the EAS Temperament Survey (Buss \& Plomin, 1984), which was completed by mothers. Recent findings suggest reasonable validity for parent ratings and moderate convergence between parent ratings and observational measures (Sanson et al., 2002). The survey yields measures on the four dimensions of Shyness (e.g., prefers playing alone), Emotionality (e.g., gets upset easily) Activity (e.g., very energetic) and Sociability (e.g., likes to be with people), with each dimension comprising five individual items. Cronbach's alphas, calculated separately from data from the US and Australia, and for boys and for girls, were all above .70 except for sociability (.56 for US boys, .55 for US girls, .56 for Australian boys, and .40 for Australian girls). Since the size of alpha is partly a function of the number of items (Green, Lissitz, \& Mulaik, 1977), and because these measures have only five items, lower alphas can be expected. The mean interitem correlation provides a further indication of internal consistency (Briggs \& Cheek, 1986). In this case, the mean inter-item correlations were above .35 for all reliabilities except for Shyness, where the mean inter-item correlation for US boys was .22, for US girls .23, for Australian boys .23, and for Australian girls .14. Mean inter-item correlations of between about .20 and .40 are considered to yield the optimum level of homogeneity (Briggs \& Cheek, 1986), as well as maximising the breadth of measurement, as suggested by Boyle (1991). Using these criteria, the internal consistencies for the temperament scales were acceptable in all cases except the Sociability measure for Australian girls.

\section{Results}

The means and standard deviations for the measures of teacher-rated child social behaviours, child temperament, and authoritative and authoritarian parenting are given in Tables 1 , 2 , and 3 respectively. The first step in the analysis was to examine mean-level difference by conducting country, sex-ofparent, and sex-of-child differences using multivariate analyses of variance (MANOVAs) and analyses of variance (ANOVAs). The second stage of the data analysis investigated individual differences using correlations and multiple regressions. The focus was on predictors of the four teacher-rated social behaviours. 
Table 1

Means and SDs for teacher-rated child behaviours (by country and child sex)

\begin{tabular}{|c|c|c|c|c|}
\hline \multirow[b]{3}{*}{ Scale } & \multicolumn{2}{|c|}{ US } & \multicolumn{2}{|c|}{ Australia } \\
\hline & $B o y s^{a}$ & Girls $^{\mathrm{b}}$ & Boys $^{\mathrm{c}}$ & Girls ${ }^{\mathrm{d}}$ \\
\hline & $M \quad(S D)$ & $M \quad(S D)$ & $M \quad(S D)$ & $M \quad(S D)$ \\
\hline Relational aggression & $0.36(0.42)$ & $0.53(0.56)$ & $0.29(0.36)$ & $0.35(0.40)$ \\
\hline Physical aggression & $0.47(0.53)$ & $0.28(0.43)$ & $0.39(0.43)$ & $0.13(0.23)$ \\
\hline Sociability & $1.25(0.56)$ & $1.34(0.55)$ & $1.14(0.59)$ & $1.25(0.50)$ \\
\hline Prosocial & $0.91(0.53)$ & $1.11(0.56)$ & $0.86(0.53)$ & $1.14(0.49)$ \\
\hline
\end{tabular}

${ }^{\mathrm{a}} n=115-124 ;{ }^{\mathrm{b}} n=85-89 ;{ }^{\mathrm{c}} n=95 ;{ }^{\mathrm{d}} n=102$.

Table 2

Means and SDs for child's temperament (by country and child sex)

\begin{tabular}{|c|c|c|c|c|}
\hline \multirow[b]{3}{*}{ Scale } & \multicolumn{2}{|c|}{$U S$} & \multicolumn{2}{|c|}{ Australia } \\
\hline & Boys $^{\mathrm{a}}$ & Girls ${ }^{\mathrm{b}}$ & Boys $^{\mathrm{c}}$ & Girls ${ }^{\mathrm{d}}$ \\
\hline & $M \quad(S D)$ & $M \quad(S D)$ & $M \quad(S D)$ & $M \quad(S D)$ \\
\hline EAS Activity & $4.15(0.67)$ & $4.08(0.65)$ & $4.02(0.77)$ & $3.81(0.75)$ \\
\hline EAS Emotional & $3.04(0.79)$ & $3.13(0.79)$ & $2.69(0.75)$ & $2.77(0.91)$ \\
\hline EAS Shy & $2.35(0.74)$ & $2.26(0.83)$ & $2.70(0.86)$ & $2.64(0.76)$ \\
\hline EAS Sociability & $3.78(0.60)$ & $3.90(0.58)$ & $3.55(0.64)$ & $3.64(0.55)$ \\
\hline
\end{tabular}

${ }^{\mathrm{a}} n=111 ;{ }^{\mathrm{b}} n=77 ;{ }^{\mathrm{c}} n=95 ;{ }^{\mathrm{d}} n=102$.

Table 3

Means and SDs for authoritative and authoritarian parenting (self-reports; total scores; by parent, country, and child sex)

\begin{tabular}{|c|c|c|c|c|c|c|c|c|c|c|c|c|c|c|c|c|}
\hline & \multicolumn{8}{|c|}{ Authoritative parenting (Total) } & \multicolumn{8}{|c|}{ Authoritarian parenting (Total) } \\
\hline & \multicolumn{4}{|c|}{ Mothers } & \multicolumn{4}{|c|}{ Fathers } & \multicolumn{4}{|c|}{ Mothers } & \multicolumn{4}{|c|}{ Fathers } \\
\hline & \multicolumn{2}{|c|}{$U S$} & \multicolumn{2}{|c|}{ Australia } & \multicolumn{2}{|c|}{ US } & \multicolumn{2}{|c|}{ Australia } & \multicolumn{2}{|c|}{ US } & \multicolumn{2}{|c|}{ Australia } & \multicolumn{2}{|c|}{$U S$} & \multicolumn{2}{|c|}{ Australia } \\
\hline & Boys & Girls & Boys & Girls & Boys & Girls & Boys & Girls & Boys & Girls & Boys & Girls & Boys & Girls & Boys & Girls \\
\hline $\begin{array}{l}\text { Mean } \\
(S D)\end{array}$ & $\begin{array}{c}3.75 \\
(0.44)\end{array}$ & $\begin{array}{c}3.81 \\
(0.47)\end{array}$ & $\begin{array}{c}3.75 \\
(0.38)\end{array}$ & $\begin{array}{c}3.83 \\
(0.44)\end{array}$ & $\begin{array}{c}3.63 \\
(0.50)\end{array}$ & $\begin{array}{c}3.66 \\
(0.46)\end{array}$ & $\begin{array}{c}3.40 \\
(0.61)\end{array}$ & $\begin{array}{c}3.62 \\
(0.57)\end{array}$ & $\begin{array}{c}2.07 \\
(0.45)\end{array}$ & $\begin{array}{c}2.06 \\
(0.45)\end{array}$ & $\begin{array}{c}2.14 \\
(0.41)\end{array}$ & $\begin{array}{c}2.08 \\
(0.46)\end{array}$ & $\begin{array}{c}2.24 \\
(0.54)\end{array}$ & $\begin{array}{c}2.21 \\
(0.44)\end{array}$ & $\begin{array}{c}2.31 \\
(0.57)\end{array}$ & $\begin{array}{r}1.97 \\
(0.45\end{array}$ \\
\hline$n$ & 97 & 65 & 90 & 97 & 63 & 51 & 53 & 53 & 97 & 65 & 90 & 98 & 64 & 51 & 53 & 53 \\
\hline
\end{tabular}

\section{Mean differences in children's social behaviour}

Separate MANOVAs were undertaken on the mean scores for the two teacher-rated aggression scales and for the two sociable scales. Country and sex-of-child were included as betweensubjects factors. For aggression, there was a between-country difference, $F(2,405)=5.48, p<.01$. Children from the US were rated higher than Australian children on both relational, $F(1,406)=8.71, p<.01$, and physical aggression, $F(1,406)$ $=8.06, p<.01$. Further, there was a sex-of-child effect, $F(2,405)=35.19, p<.001$. The follow-up ANOVAs showed that girls were rated higher than boys for relational aggression, $F(1,406)=7.05, p<.01$, whereas boys were rated higher than girls for physical aggression, $F(1,406)=28.84, p<.001$. For the two sociable scales, there was no overall multivariate effect for country. However, there was a difference between boys and girls, $F(2,391)=10.48, p<.001$. Follow-up ANOVAs showed a marginal tendency for girls to score higher than boys on the sociability scale, $F(1,392)=3.63, p<.058$, but with girls scoring higher than boys for the prosocial scale, $F(1,392)=19.82, p<.001$.

\section{Mean differences in child temperament}

The data on mother ratings of child temperament were analysed using a 2 (country) by 2 (sex of child) MANOVA. There was an effect for country, $F(4,378)=12.61, p<.001$, and an effect for sex-of-child, $F(4,378)=3.34, p<.01$. The follow-up ANOVAs showed that none of the individual temperament dimensions reached significance when boys and girls were compared. In the case of differences between countries, US children were rated higher for sociability, $F(1,381)=15.99, p<.001$, activity, $F(1,381)=2.30, p<$ .01 , and emotionality, $F(1,381)=18.25, p<.001$, and 
Australian children rated higher for shyness, $F(1,381)=$ 19.95, $p<.001$.

\section{Mean differences in authoritative and authoritarian parenting}

For parenting, the MANOVA included country and sex-ofchild as between-subjects factors and sex-of-parent as a withinsubject factor. Follow-up ANOVAs were used to explore significant effects further. The MANOVA on self-reported parenting revealed significant sex-of-parent differences, $F(2,189)=11.57, p<.001$, significant sex-of-child differences, $F(2,189)=4.71, p<.01$, and an interaction between country and sex-of-parent, $F(2,189)=4.60, p<.01$. Followup ANOVAs were undertaken on the separate measures of authoritative and authoritarian parenting. These procedures revealed that more authoritative parenting was reported by parents of girls than by parents of boys, $F(1,190)=6.39$, $p<$ .05 , with more authoritarian parenting reported for parents of boys than for parents of girls, $F(1,191)=7.06, p<.01$. Further, mothers reported more authoritative parenting than fathers, $F(1,190)=21.93, p<.001$, and fathers reported more authoritarian parenting than mothers, $F(1,191)=6.96$, $p<.01$. With respect to the country by sex-of-parent interaction in the MANOVA, the separate ANOVAs showed this to be marginally significant for both authoritative parenting, $F(1,190)=2.78, p<.097$, and authoritarian parenting, $F(1,191)=3.51, p<.062$. For authoritative parenting, there appeared to be little difference between US and Australian mothers, but US fathers were higher than Australian fathers. For authoritarian parenting, Australian mothers and fathers seemed to differ little, with US fathers scoring higher than US mothers. Finally, the ANOVA for authoritarian parenting yielded a significant country by sex-ofchild interaction, $F(1,191)=4.61, p<.05$. This seemed to arise from (1) little difference in reported authoritarian parenting with boys and girls in the US, with (2) Australian boys reported as receiving more authoritarian parenting than Australian girls.
For spouse-reported parenting, the MANOVA showed only sex-of-parent differences, $F(2,190)=18.83, p<.001$. The follow-up ANOVAs again showed mothers (as reported by fathers) scoring significantly higher on authoritative parenting $(p<.001)$, but there was no difference for authoritarian parenting. There were no significant country by sex-of-parent interactions in either of the ANOVAs. Consistent with the results for self-reported parenting, the ANOVA on spouse reports of authoritarian parenting showed higher scores for parents of boys than for parents of girls, $F(1,92)=5.08, p<$ .05 . There was also a significant country by sex-of-child interaction for spouse-reported authoritarian parenting, $F(1,192)=5.10, p<.05$. The latter seemed to arise from no difference in authoritarian parenting with US boys and girls, but higher levels with Australian boys than Australian girls.

\section{Predictions of children's behaviour: Teacher-rated sociability, prosocial, physical aggression, and relational aggression}

The second aspect of the data analyses concerned temperament and parenting factors associated with individual differences in the teacher ratings of sociability and prosocial behaviour and physical and relational aggression. Correlations between the four child social behaviours and (1) child temperament and (2) parenting are presented in Table 4 . For the temperament variables, there were no significant correlations between children's emotionality and social behaviours. As a consequence, in subsequent analyses, only the remaining three temperament variables were included. Using the $r$ to $z$ transformation procedure, preliminary analyses were conducted on boy-girl and country differences in correlations between the four child social behaviours and (1) child temperament and (2) parenting. There were no significant differences in correlations between mother and father parenting styles and the four child social behaviours for boys versus girls. On the other hand, there was one significant correlation difference (from 12 comparisons) between temperament and the four child social behaviours for boys versus girls. For country comparisons, there were

Table 4

Correlations of teacher-rated child behaviour with child temperament, self-reported parenting

\begin{tabular}{|c|c|c|c|c|}
\hline \multirow[b]{2}{*}{ Scale } & \multicolumn{4}{|c|}{ Teacher-reported child behaviour } \\
\hline & $\begin{array}{l}\text { Relational } \\
\text { aggression }\end{array}$ & $\begin{array}{l}\text { Physical } \\
\text { aggression }\end{array}$ & Sociability & $\begin{array}{l}\text { Prosocial } \\
\text { behaviour }\end{array}$ \\
\hline \multicolumn{5}{|l|}{ Temperament scales } \\
\hline EAS Activity $(n=369-381)$ & $.13^{\star}$ & $.20^{\star \star \star}$ & .10 & -.02 \\
\hline EAS Emotional $(n=369-381)$ & .02 & -.07 & .01 & .06 \\
\hline EAS Shy $(n=369-381)$ & $-.18^{\star \star \star}$ & $-.14^{\star \star}$ & $-.33^{\star \star \star}$ & $-.18^{\star \star \star}$ \\
\hline EAS Sociability $(n=369-381)$ & $.14^{\star \star}$ & .05 & $.15^{\star \star}$ & $.14^{\star \star}$ \\
\hline Mother & & & & \\
\hline $\begin{array}{l}\text { Authoritative parenting } \\
(n=349-354)\end{array}$ & -.01 & -.02 & .00 & -.06 \\
\hline $\begin{array}{l}\text { Authoritarian parenting } \\
(n=350-355) \\
\text { Father }\end{array}$ & .02 & .06 & -.06 & .03 \\
\hline $\begin{array}{l}\text { Authoritative parenting } \\
(n=210-216)\end{array}$ & -.10 & -.09 & -.01 & .02 \\
\hline $\begin{array}{l}\text { Authoritarian parenting } \\
(n=211-217)\end{array}$ & .10 & $.23^{\star \star \star}$ & -.11 & $-.19^{\star \star}$ \\
\hline
\end{tabular}

${ }^{\star} p<.05 ;{ }^{\star \star} p<.01 ;{ }^{\star \star \star} p<.001$. 
three significant correlation differences (from 16 comparisons) between parenting and the four child social behaviours and one significant difference (from 12 comparisons) between temperament and the four child social behaviours. These comparisons do not yield clear evidence of differences much beyond chance expectations. The one significant difference for sex-of-child comparisons was treated as within chance expectations, and subsequent analyses did not include sex-of-child as a factor. The three significant results for country differences in correlations involving parenting were treated as just above chance expectations and, therefore, country was included as a factor in the next set of analyses.

As the next step, separate multiple regressions with data from mothers and fathers were used to examine the predictors of the child social behaviours. Variables were entered as follows: First, a block of control variables was entered (singleversus two-parent families, sex of child, age of parent, and Hollingshead score), country, child temperament (block of three variables), parenting (block of two variables, parent selfreports), country by parenting, and temperament by parenting. In all cases, due to low power associated with interaction terms, the alpha was set at .10. These analyses revealed no country by parenting interactions. As a consequence, steps involving country in the analysis were removed and the regressions repeated. In these regressions, country was added to the block of control variables that was entered first. The results given here (summarised in Tables 5 and 6) are for the latter analyses. These contain the results for increase in variance associated with each step in the analysis plus a summary of the betas for the last step in the analysis that yielded a significant increase in variance.

In all the regression analyses, temperament contributed significantly to the prediction of child behaviour. The amount of variance explained for relational and physical aggression was relatively small and there were no significant betas for relational aggression. In the case of physical aggression, the beta for activity was positive and significant in the analyses for both mothers and fathers when the block of temperament variables was entered. In the cases of both sociability and prosocial behaviour, the beta for shyness was significant and negative for both mothers and fathers when the block of temperament variables was entered.

Father parenting contributed to both relational and physical aggression, with a significant positive beta for authoritarian style in the analysis for physical aggression. Mother parenting interacted significantly with temperament in the prediction of both sociability and prosocial behaviour. Significant betas occurred for the interaction of activity and authoritarian parenting, and sociability and authoritarian parenting in the prediction of teacher-rated sociability. In the prediction of teacher-rated prosocial behaviour, significant betas were also obtained for interactions between activity and authoritative parenting, activity and authoritarian parenting, and sociability and authoritarian parenting.

To examine these interactions further, each child temperament variable was divided using a median split. Correlations

Table 5

Results of hierarchical regressions predicting teacher-rated child behaviours from father's parenting (self-reports) and child's temperament

\begin{tabular}{lll}
\hline Dependent variable & $\Delta R^{2}$ & $F_{\text {change }}$ \\
\hline $\begin{array}{l}\text { Relational aggression } \\
\text { Temperament block }\end{array}$ & .02 & $F(8,430)=3.48^{\star}$ \\
Parenting block & .02 & $F(10,428)=3.86^{\star}$
\end{tabular}

Block of Temperament $\times$ Parenting interactions

Physical aggression

Temperament block

Parenting block
.01

Sociability

Temperament block

Parenting block

Block of Temperament $\times$ Parenting interactions Prosocial

Temperament block

Parenting block

Block of Temperament $\times$ Parenting interactions

.08

.01

.04

.01

.01
$F(10,428)=3.86^{\star}$
Predictors

\footnotetext{
${ }^{\star} p<.05 ;{ }^{\star \star} p<.01 ;{ }^{\star \star \star} p<.001$
}

EAS Sociability

EAS Shy

EAS Activity

Authoritative

Authoritarian

$F(16,422)=0.71$

$F(8,430)=2.70^{\star}$
$F(10,428)=3.46^{\star}$

$F(16,422)=0.73$

$F(8,430)=13.04^{\star \star \star}$

$F(10,428)=1.93$

$\begin{array}{lc}\text { EAS Sociability } & -.03 \\ \text { EAS Shy } & -.07 \\ \text { EAS Activity } & .10 \\ \text { Authoritative } & -.02 \\ \text { Authoritarian } & .11^{\star} \\ & \\ \text { EAS Sociability } & .03 \\ \text { EAS Shy } & -.29^{\star \star \star} \\ \text { EAS Activity } & -.02 \\ & \\ & \\ \text { EAS Sociability } & .09 \\ \text { EAS Shy } & -.17^{\star \star} \\ \text { EAS Activity } & -.09 \\ & \end{array}$

$F(10,428)=2.72$

$F(16,422)=0.54$

$29 \star \star \star$

$F(16,422)=0.65$

$F(8,430)=5.53^{\star \star \star}$

EAS Shy $-.17^{\star \star}$

$-.09$
.05

$-.10$

.06

$-.07$

.08 
Table 6

Results of hierarchical regressions predicting teacher-rated child behaviours from mother's parenting (self-reports) and child's temperament

\begin{tabular}{|c|c|c|c|c|}
\hline Dependent variable & $\Delta R^{2}$ & $F_{\text {change }}$ & Predictors & Beta \\
\hline \multicolumn{5}{|l|}{ Relational aggression } \\
\hline \multirow[t]{3}{*}{ Temperament block } & .02 & $F(8,430)=3.50^{\star}$ & EAS Sociability & .05 \\
\hline & & & EAS Shy & -.09 \\
\hline & & & EAS Activity & .06 \\
\hline Parenting block & .00 & $F(10,428)=0.91$ & & \\
\hline Block of Temperament $\times$ Parenting interactions & .01 & $F(16,422)=0.54$ & & \\
\hline \multicolumn{5}{|l|}{ Physical aggression } \\
\hline \multirow[t]{3}{*}{ Temperament block } & .02 & $F(8,430)=2.75^{\star}$ & EAS Sociability & -.03 \\
\hline & & & EAS Shy & -.06 \\
\hline & & & EAS Activity & $.10^{\star}$ \\
\hline Parenting block & .00 & $F(10,428)=0.39$ & & \\
\hline Block of Temperament $\times$ Parenting interactions & .00 & $F(16,422)=0.11$ & & \\
\hline \multicolumn{5}{|l|}{ Sociability } \\
\hline Temperament block & .08 & $F(8,430)=12.88^{\star \star \star}$ & & \\
\hline Parenting block & .00 & $F(10,428)=0.22$ & & \\
\hline \multicolumn{5}{|c|}{$\begin{array}{l}\text { Block of Temperament and Temperament } \times \text { Autoritarian } \\
\text { Parenting interactions }\end{array}$} \\
\hline & .03 & $F(16,422)=2.05 \dagger$ & EAS Sociability & .05 \\
\hline & & & EAS Shy & $-.29^{\star \star \star}$ \\
\hline & & & EAS Activity & .04 \\
\hline & & & Authoritarian by & \\
\hline & & & Shy & -.02 \\
\hline & & & Sociability & $.17^{\star \star}$ \\
\hline & & & Activity & $-.10 \dagger$ \\
\hline \multicolumn{5}{|l|}{ Prosocial } \\
\hline Temperament block & .04 & $F(8,430)=5.48^{\star \star}$ & & \\
\hline Parenting block & .01 & $F(10,428)=1.43$ & & \\
\hline \multicolumn{5}{|c|}{$\begin{array}{l}\text { Block of Temperament and Temperament } \times \text { Parenting } \\
\text { interactions }\end{array}$} \\
\hline & .03 & $F(16,422)=2.50^{\star}$ & EAS Sociability & $.09 \dagger$ \\
\hline & & & EAS Shy & $-.17^{\star \star}$ \\
\hline & & & EAS Activity & -.09 \\
\hline & & & Authoritarian by & \\
\hline & & & Shy & -.03 \\
\hline & & & Social & $.14^{\star}$ \\
\hline & & & Active & $-.15^{\star}$ \\
\hline & & & Authoritative by & \\
\hline & & & Shy & -.09 \\
\hline & & & Social & .05 \\
\hline & & & Active & $-.16^{\star \star}$ \\
\hline
\end{tabular}

$\dagger p<.10 ;{ }^{\star} p<.05 ;{ }^{\star \star} p<.01 ;{ }^{\star \star \star} p<.001$

between the parenting variables and prosocial behaviour, and between the parenting variables and sociability, were calculated for children above and below the median. These correlations were then compared using the $z$ transformation procedure.

With respect to the temperament by parenting interactions for the prediction of sociability, the median split procedure yielded correlations between authoritarian parenting and teacher-rated sociability of .07 for children above the median on temperamental sociability and -.19 for children below the median $(z=2.09, p<.05)$. The median split procedure yielded correlations between authoritarian parenting and teacher-rated sociability of -.15 for children above the median on activity and -.12 for children below the median $(z=0.17$, n.s.).

With respect to the temperament by parenting interactions for the prediction of prosocial behaviour, the correlations between authoritarian parenting and prosocial behaviour for children above and below the median on activity were -.02 and .02 respectively $(z=0.32$, n.s. $)$. For the interaction between temperament sociability and mother authoritarian parenting, the same procedure yielded correlations of .11 for children above the median and -.10 for children below the median $(z=1.71, p<.10)$. For the interaction between activity and mother authoritative parenting the correlation was -.10 for children above the median on activity and .09 for children below the median $(z=1.62, p<.11)$, a result approaching the .10 level of significance.

When the regressions predicting the four teacher-rated child outcome variables were repeated using spouse reports on parenting, temperament again contributed significantly in each analysis, with the same pattern of significant betas. In none of the analyses did parenting add significantly to the variance. In father reports on mothers there was a significant interaction between temperament and parenting, with a significant beta for the interaction between shy and authoritative parenting ( $p$ $<.10)$. 


\section{Discussion}

The results of this study confirm the importance of culture, sex/gender, and temperament in understanding children's social behaviour, and suggest important differences between the US and Australia despite the cultural similarities, for example in terms of a common "individualist" orientation. The results, therefore, suggest possible differences between Australia and the US in what Harkness et al. (2001) call parental ethnotheories; parents' culturally based models of parenting, children, and families. In a similar way, the results implicate culturally and gender-mediated socialisation sensitivities, beliefs, and practices (Chen et al., 1998). The current findings are discussed in three sections, the first dealing with mean differences, the second with predictions of children's social behaviour, and the third focusing on limitations and conclusions.

\section{Teacher-rated social behaviours and temperament difference for US versus Australia}

In support of our expectations, preschool teachers rated US children higher than Australian children on both types of aggression. These findings should be considered alongside the mother-rated differences in temperament. Contrary to earlier behavioural rating studies suggesting that Australian children are rated higher by parents on behavioural difficulties (internalising, externalising) and lower on social competency (Achenbach et al., 1990; Hensley, 1988), mothers in this study rated US children higher than Australian children on the temperamental dimensions of activity and emotionality. This suggests that Australian mothers may view underlying temperamental predispositions somewhat differently than they do overt behavioural manifestations that have been explored in past research. Supportive of past behavioural rating studies, however, American children were rated higher on sociability and lower on shyness than Australian children. Other research has also found between-country differences in rated temperament (Axia, Prior, \& Carelli, 1992; Klein \& Ballantine, 1991; Porter et al., 2002). The present results add to this body of literature by providing evidence from both teacher and parents as informants and confirm differences among countries representing Western cultures.

The temperament dimensions on which the US children were rated higher suggest active engagement with the social world or "outgoing" traits. Further, temperamental sociability and activity could be considered along with aggression as involving outgoing traits or behaviour. Consistent with this, Shiner (1998) noted that in studies of preschool boys, prosocial traits were associated with moderate levels of aggression, "perhaps because these boys were more assertive and outgoing" (p. 323). Overall, therefore, the present results suggest that the US children received higher ratings on energetic and outgoing traits from both teachers and parents than their Australian counterparts.

The parenting results could provide a possible explanation of some of the country differences in teacher-rated behaviour and temperament ratings. For self-reported authoritarian parenting, US fathers were significantly above US mothers. This difference was not evident in Australia. It is conceivable that US fathers modelled power assertive styles that were drawn on by the US children and contributed to greater aggression. Caution needs to be exercised in arriving at this conclusion, as the same difference between US mothers and fathers did not emerge from analyses of spouse reports on parenting. Apart from the effects of parenting styles, it is also possible that the US parents provided greater encouragement for outgoing traits, including self-assertion, than did Australian parents and that the Australian parents tended to emphasise more reticence in children. This latter suggestion pertains more to the content of parenting than to the style of parenting that was measured in the present research.

The possibility of US children being more "outgoing" assumes that the obtained differences in ratings are "real", (i.e., they reflect genuine differences in children's behaviour). An alternative explanation could be that the rating differences arise from contrasts in sensitivity to different forms of child behaviour in the US and Australia. For example, US parents and teachers could be more aware of and pay greater attention to outgoing traits and aggression in children. This draws on cultural differences in perceptions or interpretations of child behaviour as a component of parents' ethnotheories (Harkness et al., 2001).

Cultural differences in sensitivity to certain child behaviours, and the role of cultural norms and expectations, has been suggested by Porter et al. (2002) as a possible explanation of differences in ratings of child behaviour between the US and China. Different societal norms may engender different response metrics across cultures (Triandis, 1994), or different cultural standards for behaviour (Mueller et al., 1995). Evidence of both objective and subjective components of mothers' perceptions of their children (Bates \& Bayles, 1984) suggest one way in which cultural norms and expectations could have an impact on parent and teacher ratings of children, that is through the subjective component.

Nevertheless, it is possible that by the age of the present sample (4 years) there are some actual differences in children's traits between the countries. Actual difference could arise from cultural differences in expectations for children's behaviour, as well as contrasts in parenting practices. As Mueller et al. (1995) suggested, culture variables may influence both children's behaviour and perceptions of behaviour. This idea is consistent with the notion of cultural influences on the expression of temperament (Kerr, Lambert, \& Bem, 1996; Prior, 1992; Wachs, 1999). In Australia there may be greater pressure for the expression of shyness over the more active and outgoing dimensions of temperament, with the reverse in the United States. These possibilities need further research using different samples, research designs, and procedures.

\section{Sex-of-child differences}

Consistent with other studies of preschool-aged children (Crick, Casas, \& Mosher, 1997; Crick et al., 1999b; McNeilly-Choque et al., 1996) girls were rated by teachers as higher on relational aggression and prosocial behaviours than boys, whereas boys were rated higher on physical aggression. These sex-of-child differences held for both countries.

Temperament differences do not seem to provide an explanation of the boy-girl differences in rated relational aggression, physical aggression, and prosocial behaviours. This is because although the MANOVA comparing boys and girls on the temperament dimensions was significant, none of the follow-up analyses on the individual temperament dimensions 
were. However, there was an indication that the difference between boys and girls could be connected with parenting.

The self-report results suggested that parents were more authoritative with girls than with boys, and both self- and spouse reports suggested that parents were more authoritarian with boys than with girls. Sex-of-parent differences were also relevant here. For both self- and spouse reports, mothers were more authoritative than fathers. The self-report data also suggested that fathers were more authoritarian than mothers. With respect to the latter difference between mothers and fathers, this was especially evident in the US sample.

Suggesting that parenting styles of mothers and fathers with boys and girls is a partial explanation of sex-of-child differences in social behaviour is in accordance with claims that children model the relationships that they experience with their parents and use these same relationship styles and strategies in relationships with others (Russell, 2000; Sroufe \& Fleeson, 1986). A parallel argument is that "interactions with parents provide the context within which infants and toddlers develop and practice their social competence" (Rubin, Hastings, Chen, Stewart, \& McNichol, 1998, p. 1616). According to this argument, if girls experience more authoritative parenting than boys, involving qualities such as reasoning, warmth, and democracy, they should encounter and practise more positive relationship skills. This could assist in the development of prosocial tendencies. However, it could also contribute to a focus on relationship qualities as preferred strategies to use in aggression. The suggestion here is that when girls want to achieve their goals through aggression, they should turn to strategies with which they are familiar, in this case, relationship strategies. In turn, if boys experience more authoritarian parenting than girls, involving qualities such as physical coercion, anger, and punishment, they could develop and practise strategies and behaviour that contribute to greater use of physical aggression (Hart et al., 1992).

\section{Country and sex differences in parenting}

Consistent with other research (Hart \& Robinson, 1994; Russell et al., 1998), the results showed mothers higher on authoritative parenting than fathers and the reverse for authoritarian parenting. The result for authoritarian parenting was obtained from self-reports, but not from spouse reports. There were no main effect differences in authoritative and authoritarian parenting between the US and Australia. This result is congruent with the findings of Leung et al. (1998) based on adolescent reports of parenting in the US and Australia.

However, there was evidence of an interaction between parent sex and country. For authoritative parenting, it appeared that US fathers scored higher than Australian fathers, with little difference between US and Australian mothers. For mother-father differences in authoritarian parenting, it appeared that this result mainly applied to the US. A complication was that the interaction between sex-of-parent and country occurred for self-reports, but not for spouse reports of parenting. This raises questions about whether the results could partly arise from self-perceptions more than from behaviour. For example, US fathers might perceive themselves as using more authoritative behaviours than they actually do.

\section{Prediction of children's social behaviour}

There was little evidence of significant differences in factors predicting the teacher-rated child behaviours according to child sex or for the US versus Australia. This suggests similar processes connecting parenting and temperament to child behaviours for boys and for girls and within the US and Australia. The results also contribute to a better understanding of the separation and similarity between physical and relational aggression.

The clearest finding was that temperament qualities contributed to children's social behaviour. All four teacherrated child behaviours were linked to one or more of the parent-rated temperament dimensions. After controlling for temperament, only in the case of fathers' parenting was there evidence of contributions to the prediction of child behaviour, and then only for aggression, with authoritarian parenting a significant predictor for physical aggression. Overall, however, the results for the prediction of child social behaviour do not point to parenting styles as having a major impact on preschool children's social behaviour. Therefore, the present findings support suggestions about the role of temperament in children's social development (Rothbart \& Bates, 1998; Sanson et al., in press; Thompson, 1999). Furthermore, the significant results involving parenting occurred only when parent self-reports were used. The fact that they were not evident when spouse reports were used suggests caution should be used in interpreting the significant findings.

Shyness appeared to be the temperament characteristic most strongly and consistently related to child social behaviour (with negative contributions to physical aggression, relational aggression, sociability, and prosocial behaviour). Activity was also important, contributing positively to physical aggression and relational aggression. The pattern of results for temperament indicates that there was little specificity, in the sense that the results did not point to unique links between temperament and child social behaviour. The correlations with child temperament were not consistent with a notion of prosocial orientation and aggressive behaviours as the flip side of each other, as suggested by Shiner (1998). Rather, they are supportive of findings reported by Pepler, Craig, and Roberts (1998) indicating that aggression and prosocial behaviour can go hand in hand. Specifically, shyness was negatively related to both prosocial orientation and both types of aggression. Further, parent-rated temperamental sociability was correlated positively to teacher-rated sociability, prosocial behaviour, and relational aggression. These results suggest that at the preschool age, children displaying higher levels of both prosocial and aggressive behaviour are associated with more outgoing tendencies (lower shyness and higher sociability). Further, they suggest that prosocial orientation and relational aggression at this age are part of a broad sociability tendency. The positive relationship between sociability and relational aggression is interesting in that it implies that in order for someone to be relationally aggressive, that person has to have a certain amount of social capital (Crick et al., 1999b). In contrast to the claims of Shiner (1998), there was no evidence of aggressiveness being linked to negative emotionality (Shiner argued that the EAS emotionality scale measured negative emotionality).

Consistent with arguments that parenting could have different consequences for child development depending on the characteristics of the child (Rubin et al., 1998), evidence 
was obtained of interactions between temperament and parenting. These occurred only for mothers' self-reported parenting. Mother authoritarian parenting seemed to be linked somewhat positively with prosocial behaviour for children high on the activity dimension of temperament and somewhat negatively for children low on that dimension. This suggests that authoritarian parenting might have positive consequences for high-activity children, but some negative consequences for low-activity children. Mother authoritarian parenting also seemed to have possible negative consequences for children lower on the sociable temperament dimension. These children received lower ratings on sociability by teachers. The possible negative consequences for children's sociability and prosocial behaviour of authoritarian parenting, therefore, appears to be heightened for children lower on temperamental qualities that reflect active outgoing traits and behaviour (cf. Rubin, Burgess, $\&$ Coplan, 2002). These children are less active and prefer being alone rather than with others. For such children, the power-assertive aspects of authoritarian parenting might not provide conditions conducive to the development of sociable tendencies. These suggestions appear applicable to both the US and Australian samples.

\section{Limitations and general conclusions}

A concern in the present set of results is that findings were often present for self-reported parenting, but not for spouse reports of parenting. This further emphasises the importance of obtaining observational data in addition to self- and spouse reports as a means of clarifying differences in parenting and their effects on children. In addition, the restricted range used by parents and teachers on the rating scales could have limited the sensitivity of the measures to individual differences.

Another concern is that the samples used were from single cities in the US and Australia. Although it is possible to discuss findings and draw conclusions in terms of "the US sample" and "the Australian sample", it is problematic to generalise to conclusions about the United States versus Australia. The concurrent rather than longitudinal design is also a limitation that needs to be taken into account in drawing conclusions about possible developmental processes.

Overall, the present results reveal a pattern of findings suggesting the importance of cultural influences and gender factors for the understanding of child behaviour, child temperament, and parenting styles. The results point to important, but possibly subtle, cultural differences among individualist countries that have an impact on such things as perceptions of parenting and parenting roles, as well as on perceptions of and expectations about children's behaviour and development. With respect to linkages between parenting and child temperament to child social behaviour, the results point to possible differences for mother and father parenting, but suggest similarities in influences on child social behaviour in the United States and Australia.

Manuscript received January 2001 Revised manuscript received December 2001

\section{References}

Abe, J.A.A., \& Izard, C.E. (1999). Compliance, noncompliance strategies, and the correlates of compliance in 5-year-old Japanese and American children. Social Development, 8, 1-20.
Achenbach, T.M., Hensley, V.R., Phares, V., \& Grayson, D. (1990). Problems and competencies reported by parents of Australian and American children. fournal of Child Psychology and Psychiatry, 31, 265-286.

Achenbach, T.M., Verhulst, F.C., Baron, G.D., \& Akkerhuis, G.W. (1987). Epidemiological comparisons of American and Dutch children: I. Behavioural/emotional problems and competencies reported by parents for age 4 to 16. Fournal of the American Academy of Child and Adolescent Psychiatry, 26, 317-325.

Axia, G., Prior, M., \& Carelli, M. (1992). Cultural differences in temperament: A comparison of Italian, Italo-Australian, and Anglo-Australian toddlers. Australian Psychologist, 27, 52-56.

Bates, J.E., \& Bayles, K. (1984). Objective and subjective components of mothers' perceptions of their children from age 6 months to 3 years. MerrillPalmer Quarterly, 30, 111-130.

Block, J.H. (1983). Differential premises arising from differential socialisation of the sexes: Some conjectures. Child Development, 54, 1335-1354.

Bornstein, M.H., Haynes, O.M., Azuma, H., Galperin, C., Maitel, S., Ogino, M., Painter, I., Pscual, L., Pecheux, M.-G., Rahn, C., Toda, S., Venuti, P., Vyt, A., \& Wright, B. (1998). A cross-national study of self-evaluations and attributions in parenting: Argentina, Belgium, France, Israel, Italy, Japan, and the United States. Developmental Psychology, 34, 662-676.

Boyle, G.J. (1991). Does item homogeneity indicate internal consistency or item redundancy in psychometric scales? Personality and Individual Differences, 12, 291-294.

Briggs, S.R., \& Cheek, J.M. (1986). The role of factor analysis in the development and evaluation of personality scales. Fournal of Personality, 54, $106-148$.

Buss, A.H., \& Plomin, R. (1984). Temperament: Early developing personality traits. Hillsdale, NJ: Lawrence Erlbaum.

Carson, J.L., \& Parke, R.D. (1996). Reciprocal negative affect in parent-child interactions and children's peer competency. Child Development, 67, 22172226.

Caspi, A. (1998). Personality development across the life course. In N. Eisenberg (Ed.), Handbook of child psychology: Vol. 3: Social, emotional, and personality development (5th ed., pp. 311-388). New York: John Wiley.

Caspi, A., Henry, B., McGee, R.O., Moffitt, T.E., \& Silva, P.A. (1995). Temperamental origins of child and adolescent behaviour problems: From age three to age fifteen. Child Development, 66, 55-68.

Chao, R.K. (2001). Extending research on the consequences of parenting style for Chinese Americans and European Americans. Child Development, 72, 1832-1843.

Chen, X., Hastings, P.D., Rubin, K.H., Chen, H., Cen, G., \& Stewart, S.L. (1998). Child-rearing attitudes and behavioral inhibition in Chinese and Canadian toddlers: A cross-cultural study. Developmental Psychology, 34, 677686.

Chen, X., Li, D., Li, Z., Li., B., \& Liu, M. (2000a). Sociable and prosocial dimensions of social competence: Common and unique contributions to social, academic, and psychological adjustment. Developmental Psychology, 36, 302-314.

Chen, X.Y., Liu, M.W., \& Li, D. (2000b). Parental warmth, control and indulgence and their relations to adjustment in Chinese children: A longitudinal study. Fournal of Family Psychology, 14, 401-419.

Crick, N.R. (1996). The role of overt aggression, relational aggression, and prosocial behaviour in the prediction of children's future social adjustment. Child Development, 67, 2317-2327.

Crick, N.R., Casas, J.F., \& Ku, H.-C. (1999a). Relational and physical forms of peer victimisation in preschool. Developmental Psychology, 35, 376-385.

Crick, N.R., Casas, J.F., \& Mosher, M. (1997). Relational and overt aggression in preschool children. Developmental Psychology, 33, 579-588.

Crick, N.R., \& Werner, N.E. (1998). Response decision processes in relational and overt aggression. Child Development, 69, 1630-1639.

Crick, N.R., Werner, N.E., Casas, J.F., O’Brien, K.M., Nelson, D.A., Grotpeter, J.K., \& Markon, K. (1999b). Childhood aggression and gender: A new look at an old problem. In D. Bernstein (Ed.), The Nebraska Symposium on Motivation, Vol. 45 (pp. 75-141). Lincoln, NB: University of Nebraska Press.

Green, S.B., Lissitz, R.W., \& Mulaik, S.A. (1977). Limitations of coefficient alphas as an index of test unidimensionality. Educational and Psychological Measurement, 37, 827-838.

Harkness, S., Super, C.M., Axia, V., Eliasz, A., Palacios, J., \& Welles-Nystrom, B. (2001). Cultural pathways to successful parenting. Newsletter of International Society for the Study of Behavioural Development, 38, 9-13.

Hart, C.H., DeWolf, M, \& Burts, D.C. (1992a). Linkages among preschoolers' playground behaviour, outcome expectations, and parental disciplinary strategies. Early Education and Development, 3, 265-283.

Hart, C.H., DeWolf, M., \& Burts, D.C. (1993). Parental disciplinary strategies and preschoolers' play behaviour in playground settings. In C.H. Hart (Ed.), Children on playgrounds: Research perspectives and applications (pp. 271-313). Albany, NY: State University of New York Press. 
Hart, C.H., DeWolf, D.M., Wozniak, P., \& Burts, D.C. (1992b). Maternal and paternal disciplinary styles: Relations with preschoolers' playground behavioural orientations and peer status. Child Development, 63, 879-892.

Hart, C.H., Nelson, D.A., Robinson, C.C., Olsen, S.F., \& McNeilly-Choque, M.K. (1998). Overt and relational aggression in Russian nursery-school-age children: Parenting style and marital linkages. Developmental Psychology, 34, 687-697.

Hart, C.H., Nelson, D.A., Robinson, C.C., Olsen, S.F., McNeilly-Choque, M.K., Porter, C.L., \& McKee, T.R. (2000a). Russian parenting styles and family processes: Linkages with subtypes of victimization and aggression. In K.A. Kerns, J.M. Contreras, \& A.M. Neal-Barnett (Eds.), Family and peers: Linking two social worlds (pp. 48-84). Westport, CT: Praeger.

Hart, C.H., Newell, L.D., \& Olsen, S.F. (in press). Parenting skills and social/ communicative competence in childhood. In J.O. Green \& B.R. Burleson (Eds.), Handbook of communication and social interaction skill. Mahwah, NJ: Lawrence Erlbaum.

Hart, C.H., Olsen, S.F., Robinson, C.C., \& Mandleco, B.L. (1997). The development of social and communicative competence in childhood: Review and a model of personal, familial, and extrafamilial processes. Communication Yearbook, 20, 305-373.

Hart, C.H., \& Robinson, C.C. (1994). Comparative study of maternal and paternal disciplinary strategies. Psychological Reports, 74, 495-498.

Hart, C.H., Yang, C., Nelson, L.J., Robinson, C.C., Olsen, J.A., Nelson, D.A., Porter, C.L., Jin, S., Olsen, S.F., \& Wu, P. (2000b). Peer acceptance in early childhood and subtypes of socially withdrawn behavior in China, Russia, and the United States. International fournal of Behavioral Development, 24, 73-81.

Hensley, V.R. (1988). Australian normative study of the Achenbach Child Behavior Checklist. Australian Psychologist, 23, 371-382.

Herz, L., \& Gullone, E. (1999). The relationship between self-esteem and parenting style: A cross-cultural comparison of Australian and Vietnamese Australian adolescents. Fournal of Cross-Cultural Psychology, 30, 742-761.

Keenan, K., Shaw, D., Delliquadri, E., Giovannelli, J., \& Walsh, B. (1998). Evidence for the continuity of early problem behaviours: Application of a developmental model. Fournal of Abnormal Child Psychology, 26, 441-452.

Kerr, M., Lambert, W.W., \& Bem, D.J. (1996). Life course sequela of childhood shyness in Sweden: Comparison with the United States. Developmental Psychology, 32, 1100-1105.

Klein, H.A. \& Ballantine, J.H. (1991). Children's temperament: Patterns across cultures. Fournal of Research in Childhood Education, 6, 47-53.

Kochanska, G. (1995). Children's temperament, mothers' discipline, and security of attachment: Multiple pathways to emerging socialization. Child Development, 66, 597-615.

Kochanska, G., Kuczynski, L., \& Radke-Yarrow, M. (1989). Correspondence between mothers' self-reported and observed child-rearing practices. Child Development, 60, 56-63.

Ladd, G.W., \& Ladd, B.K. (1998). Parenting behaviours and parent-child relationships: Correlates of peer victimization in kindergarten? Developmental Psychology, 34, 1450-1458.

Lai, A.C., Zhang, Z.X., \& Wang, W.Z. (2000). Maternal child-rearing practices in Hong Kong and Beijing Chinese families: A comparative study. International fournal of Psychology, 35, 60-66.

Leaper, C. (1994). Exploring the consequences of gender segregation on social relationships. New Directions for Child Development, 65, 67-86.

Lerner, G.V. (1993). The influence of child temperamental characteristics on parent behaviors. In T. Luster \& L. Okagaki (Eds.), Parenting: An ecological perspective (pp. 101-120). Hillsdale, NJ: Lawrence Erlbaum.

Leung, K., Lau, S., \& Lam, W.L. (1998). Parenting styles and academic achievement: A cross-cultural study. Merrill-Palmer Quarterly, 44, 157-172.

Maccoby, E.E., \& Martin, J.A. (1983). Socialisation in the context of the family: Parent-child interaction. In E.M. Hetherington (Ed.), Handbook of child psychology: Vol. 4. Socialisation, personality, and social development (4th ed., pp. 1-101). New York: John Wiley.

MacDonald, K., \& Parke, R.D. (1984). Bridging the gap: Parent-child play interaction and peer interactive competence. Child Development, 55, 12651277.

McNeilly-Choque, K.K., Hart, C.H., Robinson, C.C., Nelson, L.J., \& Olsen, S.F. (1996). Overt and relational aggression on the playground: Correspondence among different informants. Fournal of Research in Childhood Education, 11, 47-67.

Mize, J., \& Pettit, G.S. (1997). Mothers' social coaching, mother-child relationship style, and children's peer competence: Is the medium the message? Child Development, 68, 312-332.

Mueller, C.W., Mann, E.M., Thanapum, S., Humris, E., Ikeda, Y., Takahashi, A., Tao, K., \& Li, B.L. (1995). Teachers' ratings of disruptive behaviour in five countries. Fournal of Clinical Child Psychology, 24, 434-442.

Pachter, L.M., \& Harwood, R.L. (1996). Culture and child behaviour and psychosocial development. Development and Behavioral Pediatrics, 17, 191198.

Parke, R.D., Simpkins, S.D., McDowell, D.J., Kim, M., Killian, C., Dennis, J., Flyr, M.L., Wild, M., \& Rah, Y. (2002). Relative contributions of families and peers to children's social development. In P.K. Smith \& C.H. Hart (Eds.),
Blackwell Handbook of childhood social development. (pp. 156-177). Oxford: Blackwell.

Pavuluri, M., \& Luk, S.-L. (1996). Pattern of preschool behaviour problems in New Zealand, using the Behaviour Check List. Fournal of Paediatrics and Child Health, 32, 132-137.

Pepler, D.J., Craig, W.M., \& Roberts, W.L. (1998). Observations of aggressive and nonaggressive children on the school playground. Merrill-Palmer Quarterly, 44, 55-76.

Pettit, G.S., Brown, E.G., Mize, J., \& Lindsey, E. (1998). Mothers' and fathers' socialising behaviours in three contexts: Links with children's peer competence. Merrill Palmer Quarterly, 44, 173-193.

Pettit, G.S., Clawson, M.A., Dodge, K.A., \& Bates, J.E. (1996). Stability and change in peer-rejected status: The role of child behaviour, parenting and family ecology. Merrill Palmer Quarterly, 42, 267-294.

Porter, C.L., Hart, C.H., Yang, C., Zeng, Q., \& Robinson, C.C. (2002). An exploratory study of child temperament and parenting: Chinese and US comparisons. Paper under review and presented at the XVIth Biennial Meeting of the International Society for the Study of Berhavioral Development, Beijing, China, July 11-14, 2000.

Power, T.G., McGrath, M.P., Hughes, S.O., \& Manire, S.H. (1994). Compliance and self-assertion: Young children's responses to mothers versus fathers. Developmental Psychology, 30, 980-989.

Prior, M. (1992). Childhood temperament. Fournal of Child Psychology and Psychiatry and Allied Disciplines, 33, 249-270.

Robinson, C.C., Hart, C.H., Mandleco, B.L., Olsen, S.F., Russell, A., Aloa, V., Jin, S., Nelson, D.A., \& Bazarskaya, N. (1996). Psychometric support for a new measure of authoritative, authoritarian, and permissive parenting practices: Crosscultural connections. Paper presented to Biennial Conference of International Society for the Study of Behavioral Development, Quebec City, Canada, August.

Robinson, C.C., Mandleco, B., Olsen, S.F., \& Hart, C.H. (2001). Parenting Styles and Dimensions Questionnaire. In B.F. Perlmutter, J. Touliatos, \& G.W. Holdern (Eds.), Handbook of family measurement techniques: Instruments and index (pp. 319-321). Thousand Oaks, CA: Sage.

Rothbart, M.K., \& Bates, J.E. (1998). Temperament. In N. Eisenberg (Vol. Ed.) and W. Damon (Ed.), Handbook of child psychology: Vol. 3. Social, emotional and personality development (5th ed., pp. 105-176). New York: John Wiley.

Rubin, K.H., Burgess, K., \& Coplan, R. (2002). Social withdrawal and shyness. In P.K. Smith \& C.H. Hart (Eds.), Blackwell handbook of childhood social development (pp. 329-352). Oxford, UK: Blackwell.

Rubin, K.H., Hastings, P., Chen, X., Stewart, S., \& McNichol, K. (1998). Intrapersonal and maternal correlates of aggression, conflict, and externalising problems in toddlers. Child Development, 69, 1614-1629.

Ruble, D.N., \& Martin, C.L. (1998). Gender development. In W. Damon (Ed. in Chief) and N. Eisenberg (Vol. Ed.), Handbook of child psychology, 5th ed. Volume 3: Social, emotional, and personality development (pp. 933-1016). New York: John Wiley.

Rudy, D., Grusec, J.E., \& Wolfe, J. (1999). Implications of cross-cultural findings for a theory of family socialisation. Fournal of Moral Education, 28, 299-310.

Russell, A. (2000). Sex differences in children's relationship learning. In R. Mills \& S. Duck (Eds.), Developmental psychology of personal relationships (pp. 109129). Chichester, UK: John Wiley.

Russell, A., Aloa, V., Feder, T., Glover, A., Miller, H., \& Palmer, G. (1998). Sex-based differences in parenting styles in a sample with preschool children. Australian fournal of Psychology, 50, 89-99.

Russell, A., \& Russell, G. (1992a). Child effects in socialisation research: Some conceptual and data analysis issues. Social Development, 2, 163-184.

Russell, A., \& Russell, G. (1992b). The socialisation of Australian boys and girls in middle childhood for independence and achievement. In J.L. Roopnarine \& D.B. Carter (Eds.), Annual advances in applied developmental psychology: Vol. 5. Parent-child socialisation in diverse cultures (pp. 53-74). Norwood, NJ: Ablex.

Russell, A., \& Russell, G. (1996). Positive parenting and boys' and girls' misbehaviour during a home observation. International fournal of Behavioral Development, 19, 291-307.

Sanson, A., \& Rothbart, M.K. (1995). Child temperament and parenting. In M.H. Bornstein (Ed.), Handbook of parenting: Vol. 4. Applied and practical parenting (pp. 299-321). Mahwah, NJ: Erlbaum.

Sanson, A., Hemphill, S.A., \& Smart, D. (2002). Temperament and social development. In P.K. Smith \& C.H. Hart (Eds.), Blackwell handbook of childhood social development (pp. 97-116). Oxford: Blackwell.

Shiner, R.L. (1998). How shall we speak of children's personalities in middle childhood? A preliminary taxonomy. Psychological Bulletin, 124, 308-332.

Sroufe, L.A., \& Fleeson, J. (1986). Attachment and the construction of relationships. In W.W. Hartup \& Z. Rubin (Eds.), Relationships and development (pp. 51-72). Hillsdale, NJ: Lawrence Erlbaum.

Stanger, C., Fombonne, E., \& Achenbach, T.M. (1994). Epidemiological comparisons of American and French children: Parent reports of problems and competencies for ages 6-11. European Child and Adolescent Psychiatry, 3, $16-28$. 
Stewart, S.M., \& McBride-Chang, C. (2000). Influences on children's sharing in a multicultural setting. Fournal of Cross-Cultural Psychology, 31, 333-348.

Thompson, R.A. (1999). The individual child: Temperament, emotion, self, and personality. In M.H. Bornstein \& M.E. Lamb (Eds.), Developmental psychology: An advanced textbook (4th ed., pp. 377-409). Mahwah, NJ: Lawrence Erlbaum.

Tomada, G., \& Schneider, B.H. (1997). Relational aggression, gender, and peer acceptance: Invariance across culture, stability over time, and concordance among informants. Developmental Psychology, 33, 601-609.

Triandis, H.C. (1994). Culture and social behaviour. New York: McGrawHill.

Wachs, T.D. (1999). The what, why, and how of temperament: A piece of the action. In L. Balter, \& C. Tamis-LeMonda (Eds.), Child psychology: $A$ handbook of contemporary issues (pp. 23-44). Philadelphia, PA: Psychology Press.
Walker, H.M., \& Lamon, W.E. (1987). Social behaviour standards and expectations of Australian and US teacher groups. The fournal of Special Education, 21, 56-82.

Weisz, J.R., Chaiyasit, W., Weiss, B., Eastman, K.L., \& Jackson, E.W. (1995). A multimethod study of problem behaviour among Thai and American children in school: Teacher reports versus direct observation. Child Development, 1995, $66,402-415$.

Wu, P., Robinson, C.C., Yang, C., Hart, C.H., Olsen, S.F., Porter, C.L., Jin, S., Wo, J., \& Wu, X. (2002). Similarities and differences in mothers' parenting of preschoolers in China and the United States. International fournal of Behavioral Development, 26, 481-491.

Xiao, H. (1999). Independence and obedience: An analysis of child socialisation values in the United States and China. Fournal of Comparative Family Studies, 30, 641-657.

Zahn-Waxler, C. (1993). Warriors and worriers: Gender and psychopathology. Development and Psychopathology, 2, 271-291. 
Copyright of International Journal of Behavioral Development is the property of Psychology Press (T\&F) and its content may not be copied or emailed to multiple sites or posted to a listserv without the copyright holder's express written permission. However, users may print, download, or email articles for individual use. 